\title{
RADIOGRAPHIC VISUALIZATION OF ARTERIAL LESIONS IN CHOLESTEROL-FED RABBITS
}

\author{
Effect of Clofibrate, and of Return to Normal Diet on Serum \\ Cholesterol, and on Lesion Status \\ MICHAEL SUGAR, DAVID R. BASSETT, M.D., \\ JOSEPH J. BOOKSTEIN, M.D., AND \\ J. CHRISTOPHER HOUGH
}

\section{INTRODUCTION}

Since the pioneer studies of Anitschkow, ${ }^{1}$ attempts have been made in experimental animals to show that reduction in serum lipids results in regression of atherosclerotic lesions. Rodbard, et al., ${ }^{2}$ Buchwald, ${ }^{3}$ and Armstrong, et al., ${ }^{4}$ have reported improvement in experimentally-induced atherosclerotic lesions following reduction of serum lipids in chickens, rabbits, and rhesus monkeys respectively. These studies have involved the sacrifice of one group of experimental animals at an appropriate time to demonstrate that atherosclerosis has been induced, and a continuation of one or more groups of experimental animals beyond that point, exposing them to the therapeutic agent or return to lipidlowering diet, and noting the degree of atherosclerosis in those animals.

It would be desirable if arteriographic studies could be conducted in the same animal at several points in time, without significantly harmful results. If this were possible, the same animal could be followed through several experimental periods, and the effect of drug or dietary change on the status of arterial integrity noted in each experimental animal.

We have undertaken to determine, in rabbits rendered atherosclerotic by cholesterol feeding: 1) whether radiographs of large vessels could be obtained on three separate occasions in individual rabbits; 2) whether animals given clofibrate in addition to cholesterol feeding might develop a lesser degree of atherosclerosis than rabbits fed cholesterol without clofibrate; and 3) the degree of atherosclerosis in rabbits fed the cholesterol diet for two months only, followed by three months on normal diet.

\section{MATERIALS AND METHODS}

Male New Zealand white rabbits, weighing $3-4 \mathrm{~kg}$ at the start of study, were divided into three experimental groups (see Table 1 for structure of protocol).

Rabbits were housed in individual cages. They were fed Purina Rabbit Chow throughout, with the addition of other elements as described below. Water was given ad lib, with $0.09 \%$ sulfaquinoxaline added during the first two weeks to combat infections.

From the Departments of Internal Medicine and Radiology, University of Michigan Medical Center, Ann Arbor, Michigan 48104. 
During a baseline period (Period I) lasting one to several weeks, only Purina Rabbit Chow was fed to each group. Initial determinations of serum cholesterol were made during this period, and baseline arteriographic studies were performed on approximately half the animals in each group. The 16 rabbits of group A were then given $1 \%$ cholesterol and $4 \%$ cottonseed oil added to the diet for two months (Period II), followed by one month of regular diet (Period III). In Period IV, lasting at least two months, $1 \%$ cholesterol and $4 \%$ cottonseed oil were added as in Period II. The rationale for the intermittent cholesterol diet was to produce recurrent severe hyperlipidemia, but with less risk of death from hepatic lipid infiltration than would occur if the diet were fed continuously. This regimen is associated with the production of severe atherosclerosis in 2-6 months. ${ }^{5}$

The 14 rabbits in group B followed a similar protocol, except that Atromid-S (chlorophenoxyisobutyrate) ${ }^{*} 0.3 \% \mathrm{~W} / \mathrm{W}$ was added to the diet during Periods II, III, and IV.

The 14 rabbits in group C followed the same diet as group A during Period II (Rabbit Chow plus cholesterol plus cottonseed oil) and Period III (Rabbit Chow, without added lipid). (Two of these animals did not have baseline cholesterol levels determined.) However, the regular Rabbit Chow diet, without added lipid, was administered during Period IV. The purpose of group B was to test the effect of clofibrate in preventing progression of lesions; the purpose of the regular diet in group $\mathrm{C}$ was to test the effect of return to such a diet on reduction of serum lipids, and on regression of lesions.

Approximately half the rabbits in each group had an initial aortic and femoral arteriogram performed during the baseline period. The technique involved visualization of the distal aorta and leg arteries by injection of $50 \%$ diatrizoate sodium (Hypaque ${ }^{\circledR}$ ) in the initial studies; in the later studies, $60 \%$ meglumine iothalamate (Conray $\left.{ }^{(}\right)$was used, since this appeared to be better tolerated by the animals. ${ }^{6}$ The right carotid artery was used for insertion of catheter, by cutdown. $\dagger$

Repeat arteriogram was done at the end of Period II, catheterizing one femoral artery and injecting radiopaque material at the aortic bifurcation thus visualizing the opposite femoral artery. The femoral artery used for catheterization was then tied off. At the end of at least five months from beginning of studies, a final arteriogram was done, entering the opposite femoral artery and visualizing the leg arteries distal to this point.

During the latter period of the study, when the second group of rabbits (24 of the total 44) were begun on the protocol, the initial arteriogram was not done.

* Kindly supplied by Jerome Noble, M.D., Director of Clinical Research, Ayerst Laboratories.

$\dagger$ Details of catheterization procedures with pertinent references, have been submitted to the American Documentation Institute. For this information, order NAPS Document NAPS- from ASIS National Auxiliary Publications Service, $\%$ CCM Information Sciences, Inc.. 22 West 34th Street, New York, New York 10001; remitting $\$ 1.00$ for microfiche or $\$ 3.00$ for photocopies. 
In some of these rabbits, the arteriogram was performed at the end of Period II, and eight rabbits in this second group had arteriography performed at the close of Period IV, using a right carotid arterial approach, with injection above the renal arteries, followed by another injection at the bifurcation of the abdominal aorta. (The mid-aortic injections were done to determine whether renal artery stenosis could be demonstrated. Delineation of renal arteries was less clear than that obtained for ileofemoral and popliteal vessels; further work is required to determine optimal conditions for renal artery visualization.)

Blood was obtained from an ear artery, and serum cholesterol performed by the method of Abell, et al. ${ }^{7}$ at the points indicated in Table 1 (baseline; after 30 and 60 days in Period II; after 30 days in Period III; and after approximately 30 and 60 days in Period IV). At the end of Period IV, and following the final arteriogram, animals were sacrificed, and autopsies performed on representative animals from each group.

As will be seen from Table 1, a number of rabbits died during the study. The causes included sepsis, mucous enteritis, middle ear infections, and apparent hepatic failure. The animals which survived through Period IV appeared to be free of these diseases.

Data on individual animals have been tabulated and submitted to the American Documentation Institute.*

\section{RESULTS}

\section{Serum cholesterol}

Table 1 and figure 1 presents the results of the dietary and drug regimens on serum cholesterol concentration. All groups developed significant hyperlipidemia during the two months of Period II. The serum lipids declined significantly during the one month of regular diet (Period III). Serum cholesterol returned nearly to normal in group $\mathrm{C}$ after two more months on regular diet, whereas it rose promptly again in group A (cholesterol and cottonseed oil) and group B (cholesterol plus cottonseed oil plus clofibrate). In general, specimens which were hypercholesterolemic were lactescent, indicating that a considerable rise in serum triglyceride concentration must also have accompanied the hypercholesterolemia.

Clofibrate did not appear to improve the hypercholesterolemia in the rabbits receiving it during Periods II, III, or IV (study group B).

Since a number of rabbits did not survive to the end of Period IV, calculations of mean serum cholesterol of those surviving, and those not surviving to the end of Period IV were made for each of the sampling points in groups A, B, and C. No significant differences were noted between "survivors", and "non-survivors" at any of these times.

* For supplementary tables, order NAPS Document * NAPSfrom ASIS National Auxiliary Publications Service, \% CCM Information Sciences. Inc.. 22 West 34th Street, New York, New York 10001; remitting $\$ 1.00$ for microfiche or $\$ 3.00$ for photocopies. 


\section{TABLE 1}

Serum cholesterol concentration in experimental and control rabbits. Mean Values, \pm Standard Error of Mean

\begin{tabular}{|c|c|c|c|c|c|c|}
\hline \multirow{2}{*}{$\begin{array}{l}\text { Period } \ldots \ldots \ldots \ldots \\
\text { Time after onset of diet } \ldots \ldots \ldots \ldots \ldots\end{array}$} & \multirow{2}{*}{$\begin{array}{c}\text { I } \\
\text { Baseline }\end{array}$} & \multicolumn{2}{|c|}{ II } & \multirow{2}{*}{$\begin{array}{c}\text { III } \\
90 \text { Days }\end{array}$} & \multicolumn{2}{|c|}{ IV } \\
\hline & & 30 Days & 60 Days & & $120+$ Days & $150 \dagger$ Days \\
\hline Group $A$ & $\begin{array}{l}\text { Rabbit } \\
\text { chow } \\
\text { (RC) }\end{array}$ & \multicolumn{2}{|c|}{$\begin{array}{c}\mathrm{RC}+1 \% \text { chol }+ \\
4 \% \text { cottonseed } \\
\text { (ctnsd) oil }\end{array}$} & $\mathrm{RC}$ & \multicolumn{2}{|c|}{$\begin{array}{l}\mathrm{RC}+1 \% \text { chol }+ \\
4 \% \text { ctnsd oil }\end{array}$} \\
\hline $\begin{array}{l}\text { Serum chol (mg\%) } \\
\text { S.E. } \\
\text { Number of animals studied } \\
\text { p value, A vs B } \\
\qquad \text { A vs C }\end{array}$ & $\begin{array}{l}52^{* * *_{1}} \\
6 \\
(15) \\
\text { NS } \\
\text { NS }\end{array}$ & $\begin{array}{c}1245 \mathrm{NS} \\
106 \\
(16) \\
\mathrm{NS} \\
\mathrm{NS}\end{array}$ & $\begin{array}{l}1469^{*}+ \\
158 \\
(15) \\
\text { NS } \\
\text { NS }\end{array}$ & $\begin{array}{l}359^{* *+}+ \\
57 \\
(9) \\
\text { NS } \\
\text { NS }\end{array}$ & $\begin{array}{c}1497 \text { NS } \\
555 \\
(3) \\
\text { NS } \\
\text { tft }\end{array}$ & $\begin{array}{c}1265 \\
218 \\
(6) \\
\mathrm{NS} \\
* * *\end{array}$ \\
\hline Group $B$ & $\mathrm{RC}$ & \multicolumn{2}{|c|}{$\begin{array}{c}\mathrm{RC}+1 \% \text { chol }+ \\
4 \% \text { ctnsd oil }+ \\
0.3 \% \text { clofibrate }\end{array}$} & $\begin{array}{l}\mathrm{RC}+0.3 \% \\
\text { clofibrate }\end{array}$ & \multicolumn{2}{|c|}{ Same as Period II } \\
\hline $\begin{array}{l}\text { Serum chol (mg\%) } \\
\text { S.E. } \\
\text { Number of animals studied } \\
\text { p value, B vs C }\end{array}$ & $\begin{array}{l}48^{* * *} \\
4 \\
(13) \\
\text { NS }\end{array}$ & $\begin{array}{l}1322 \mathrm{NS} \\
183 \\
(14) \\
\mathrm{NS}\end{array}$ & $\begin{array}{l}1815^{* * *} \\
212 \\
(10) \\
\text { NS }\end{array}$ & $\begin{array}{l}452^{* *}+ \\
112 \\
(7) \\
\mathrm{NS}\end{array}$ & $\begin{array}{c}1514 \mathrm{NS} \\
260 \\
(4) \\
\dagger \dagger \dagger\end{array}$ & $\begin{array}{r}1766 \\
90 \\
(4) \\
* * *\end{array}$ \\
\hline Group C & $\mathrm{RC}$ & \multicolumn{2}{|c|}{$\begin{array}{c}\mathrm{RC}+1 \% \text { chol } \\
4 \% \text { ctnsd oil }\end{array}$} & $\mathrm{RC}$ & \multicolumn{2}{|c|}{$\mathrm{RC}$} \\
\hline $\begin{array}{l}\text { Serum chol }(\mathrm{mg} \%) \\
\text { S.E. } \\
\text { Number of animals studied }\end{array}$ & $\begin{array}{l}54^{* * *} \\
12 \\
(12)\end{array}$ & $\begin{array}{l}1240 \mathrm{NS} \\
249 \\
(10)\end{array}$ & $\begin{array}{c}1459^{*} \\
318 \\
(6)\end{array}$ & $\begin{array}{l}328+\dagger \cdot \dagger \dagger \dagger \\
66 \\
(3)\end{array}$ & $\begin{array}{c}138 \mathrm{NS} \\
\frac{(2)}{1}\end{array}$ & $\begin{array}{c}154 \\
34 \\
(8)\end{array}$ \\
\hline
\end{tabular}

Chol = cholesterol.

${ }^{1} \mathrm{p}$ value (t test): (present column vs. next column to the right.)

$*=p<.05$

$*+=\mathrm{p}<.025$

$* *=\mathrm{p}<.01$

$* *+=\mathrm{p}<.005$

$* * *=\mathrm{p}<.001$

$\dagger$ approximate time interval

$\dagger \dagger$ one animal, with chol apparently $=1179$, not included

$\dagger \dagger \dagger$ not tested, since $\mathrm{n}=2$ for group $\mathrm{C}$.

\section{Radiographic findings}

Table 2 and figure 2 present the radiographic findings obtained in Periods I, II, and IV. Eighteen baseline X-rays were obtained. The visualized arteries appeared normal. At the close of Period II, 20 radiographs were obtained (10, 7, and 3 in groups $\mathrm{A}, \mathrm{B}$, and $\mathrm{C}$ respectively). Two animals in group $\mathrm{A}$, and one in 


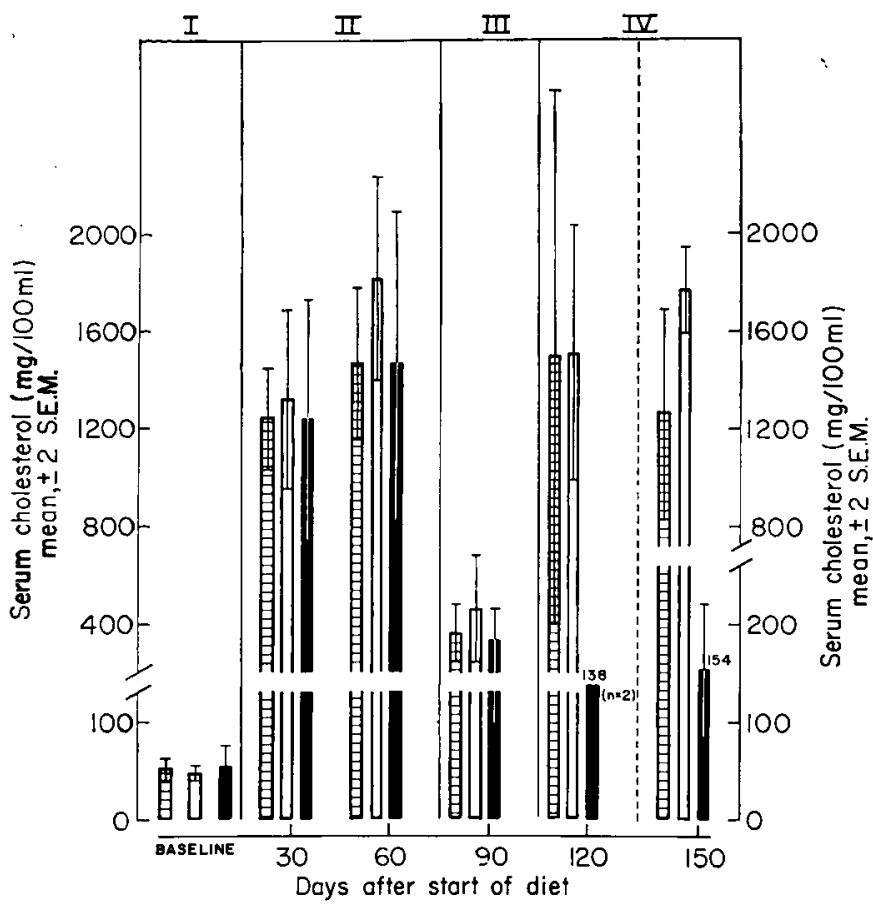

FIG. 1. Serum cholesterol concentration in response to $1 \%$ cholesterol-4\% cottonseed oil added to diet; to clofibrate; and to resumption of normal diet. Cross-hatched bars $=$ group A ( $1 \%$ cholesterol $-4 \%$ cottonseed oil added to diet in periods II and IV). Open bars = group B $(0.3 \%$ clofibrate $\mathrm{W} / \mathrm{W}$ added in periods II, III, and IV; otherwise same as A). Solid bars $=$ group $C$ ( $1 \%$ cholesterol $-4 \%$ cottonseed oil added to diet in period II. Return to normal rabbit chow in periods III and IV). N.B. Use R-hand scale for values in final phase of period IV.

TABLE 2

Angiographic Findings in Experimental and Control Rabbits

\begin{tabular}{|c|c|c|c|c|}
\hline & $\begin{array}{c}\text { Period I } \\
\text { Initial X-ray }\end{array}$ & $\underset{\mathrm{X} \text {-ray } 60^{*} \text { Days }}{\text { Period II }}$ & Period & $\begin{array}{c}\text { Period IV } \\
\text { X-ray } 150^{*} \text { Days }\end{array}$ \\
\hline \multicolumn{5}{|l|}{ Group A } \\
\hline Total animals studied & 7 & 10 & & 7 \\
\hline * animals abnormal & 0 & 2 & & 4 \\
\hline \multicolumn{5}{|l|}{ Group B } \\
\hline Total animals studied & 5 & 7 & & 5 \\
\hline * animals abnormal & 0 & 1 & & 4 \\
\hline \multicolumn{5}{|l|}{ Group C } \\
\hline Total animals studied & 6 & 3 & & 4 \\
\hline * animals abnormal & 0 & 0 & & 1 \\
\hline
\end{tabular}

* approximate time interval after cholesterol feeding begun for first time. 


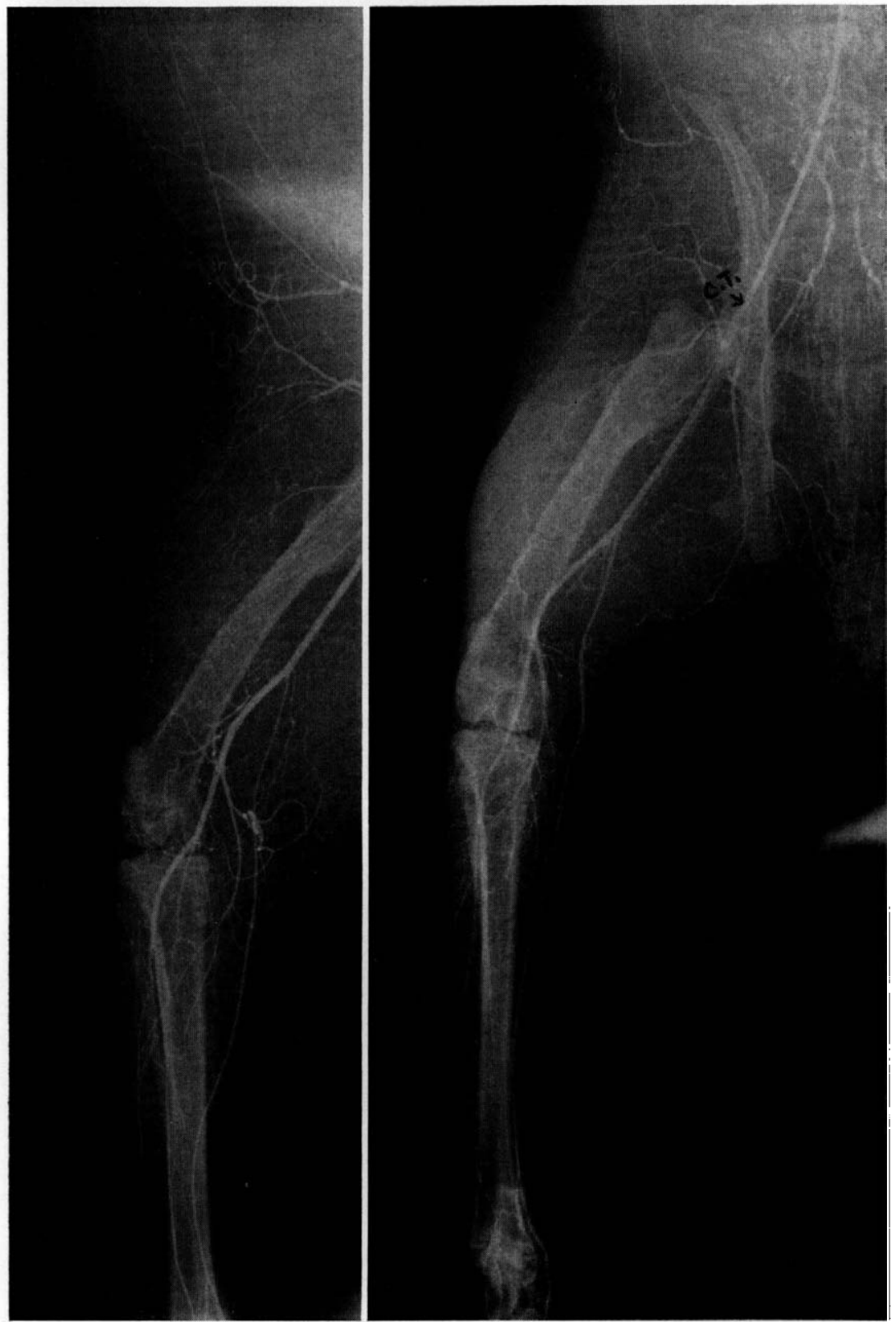

Fig. 2a. Representative normal X-rays-baseline (Period I); 2a. (Rabbit Group A \$56; cholesterol $=71 \mathrm{mg} \%$ ); 2a. . (Rabbit Group C $\$ 50$; cholesterol $=137 \mathrm{mg} \%$ ).

group B had irregularities of arterial outline which may represent atherosclerotic or thrombotic lesions. (In group A, rabbit 30 showed a narrowing in a small branch artery; rabbit 56 revealed a possible narrowing in a small branch vessel, of uncertain significance. In group B, rabbit 31 revealed an 


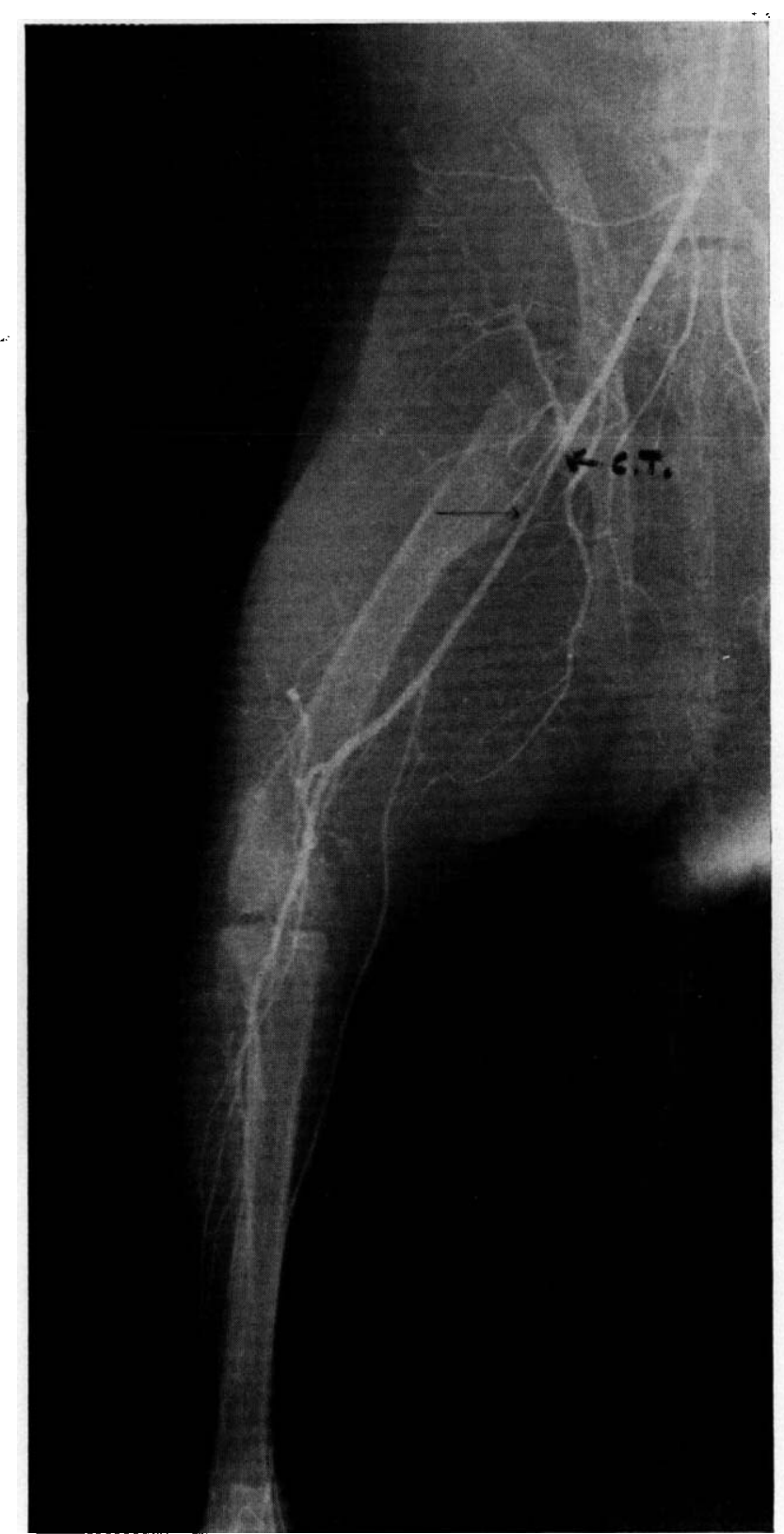

Fia. 2b. X-ray from baseline (Period I) with artefactual constriction distal to catheter tip (C.T.) (Rabbit Group A $\$ 30$; cholesterol $=42 \mathrm{mg} \%$ ). 

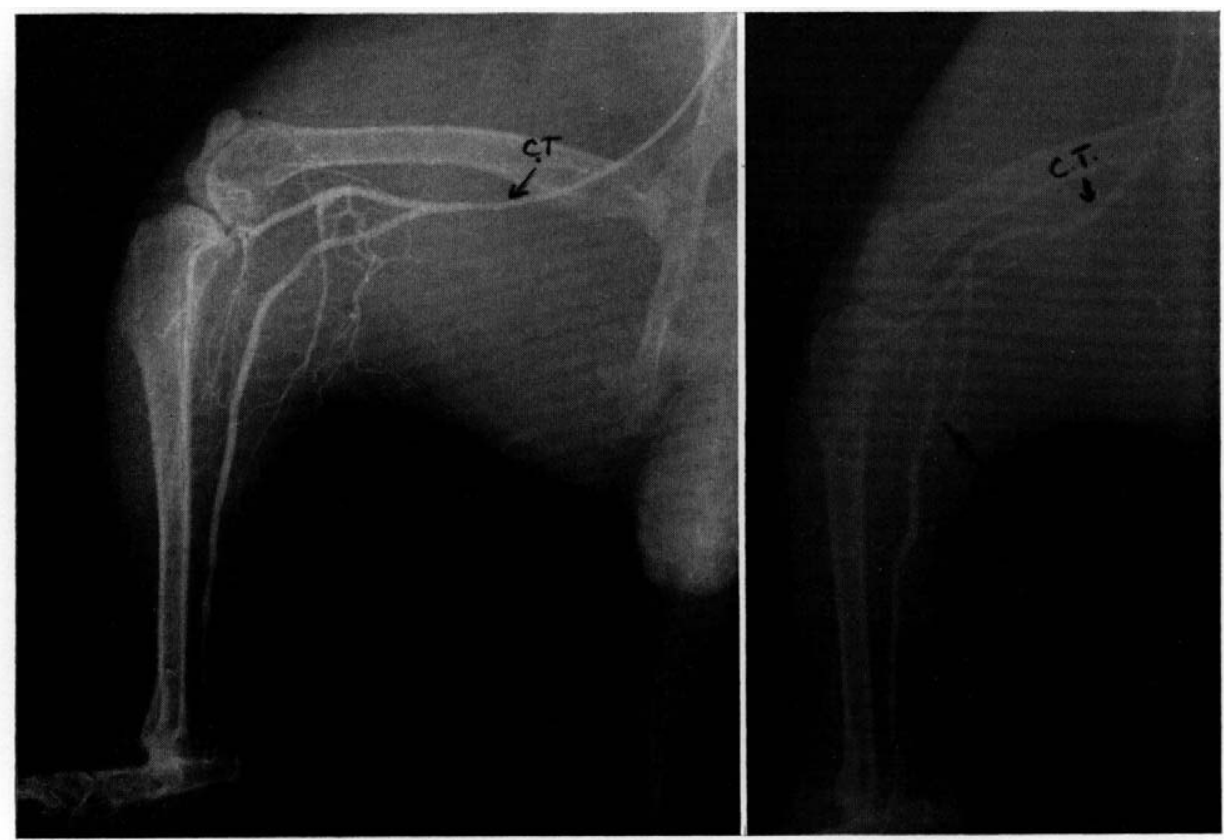

Fra. 2c $c_{1}$ X-ray from Period IV, Group A (after two 2-month periods of $1 \%$ cholesterol$4 \%$ cottonseed oil, interspersed with one month of normal rabbit chow diet). (Note stenosis of popliteal artery.) (Rabbit Group A 34 ; cholesterol $=1429 \mathrm{mg} \%$.) 2ce. (Rabbit Group A 56 ; cholesterol $=2603 \mathrm{mg} \%$ at 120 days.)

apparent occlusion of the left ilio-lumbar artery approximately $1 \mathrm{~cm}$ from its origin.)

After at least 60 days of Period IV, 16 radiographs were obtained $(7,5$, and 4 in groups $A, B$, and $C$ respectively). Four of the seven in group $A$, four of the five in group $B$, and one of the four in group $C$ had irregularities of arterial outline which suggested atherosclerosis, a possibility strengthened by the finding, particularly in groups $\mathrm{A}$ and $\mathrm{B}$, of atherosclerosis by anatomic examination, in the aorta and other large vessels.

\section{Anatomic findings}

Table 3 and figure 3 present the observations made at autopsy. Of six group A rabbits autopsied, four had severe atherosclerosis, most markedly in the thoracic aorta, and two had moderately severe atherosclerosis. Of interest was the considerable atherosclerotic involvement of the pulmonary arteries, especially in the main pulmonary artery, but also at points of branching and presumed turbulence.

Of the seven group B rabbits autopsied, four had severe atherosclerosis, most notable in the thoracic aorta. Two had moderate atherosclerosis, and one had mild atherosclerosis of the major vessels (this animal, 77 , had initial cholesterol concentration of $35 \mathrm{mg} \%, 1,007 \mathrm{mg} \%$ at 30 days, $425 \mathrm{mg} \%$ at 90 days, and $1,502 \mathrm{mg} \%$ at approximately 150 days). 
TABLE 3

Grading* of vascular lesions seen at autopsy

\begin{tabular}{|c|c|c|c|c|c|}
\hline Group & Animal No. & Heart & $\begin{array}{c}\text { Pulmonary } \\
\text { Arteries }\end{array}$ & $\begin{array}{c}\text { Thoracic } \\
\text { Aorta }\end{array}$ & $\underset{\text { Aorta }}{\text { Abdominal }}$ \\
\hline$A$ & 53 & - & 3 & 3 & 3 \\
\hline \multirow[t]{5}{*}{$\therefore$} & 60 & 2 & 1 & 2 & 1 \\
\hline & 66 & 1 & 1 & 3 & 2 \\
\hline & 67 & 1 & 1 & 3 & 1 \\
\hline & 68 & 2 & 2 & 3 & 3 \\
\hline & 80 & 2 & - & 一 & - \\
\hline \multirow[t]{6}{*}{$\mathbf{B}$} & 39 & 2 & 1 & 1 & - \\
\hline & 45 & 2 & 2 & 3 & - \\
\hline & 57 & 2 & 2 & 3 & - \\
\hline & 73 & 2 & 2 & 1 & 2 \\
\hline & 76 & - & - & 3 & - \\
\hline & 77 & 1 & 1 & 1 & 1 \\
\hline . & 78 & 2 & 2 & 3 & 2 \\
\hline \multirow[t]{4}{*}{$\mathbf{C}$} & 46 & 2 & 1 & 3 & 3 \\
\hline & 50 & 1 & 1 & 2 & 1 \\
\hline & 81 & 0 & 0 & 0 & 0 \\
\hline & 85 & 0 & 0 & 0 & 0 \\
\hline
\end{tabular}

* $0=$ within normal limits (intima free of grossly visible atheromata)

$1=$ mild atherosclerosis (few atheromata, principally at ostia of vessels, and at other points of turbulence)

$2=$ moderate atherosclerosis $(1 / 3$ to $2 / 3$ of intima involved with atheromata)

$3=$ severe atherosclerosis (intima largely or completely involved with atheromata)

$-=$ not described.

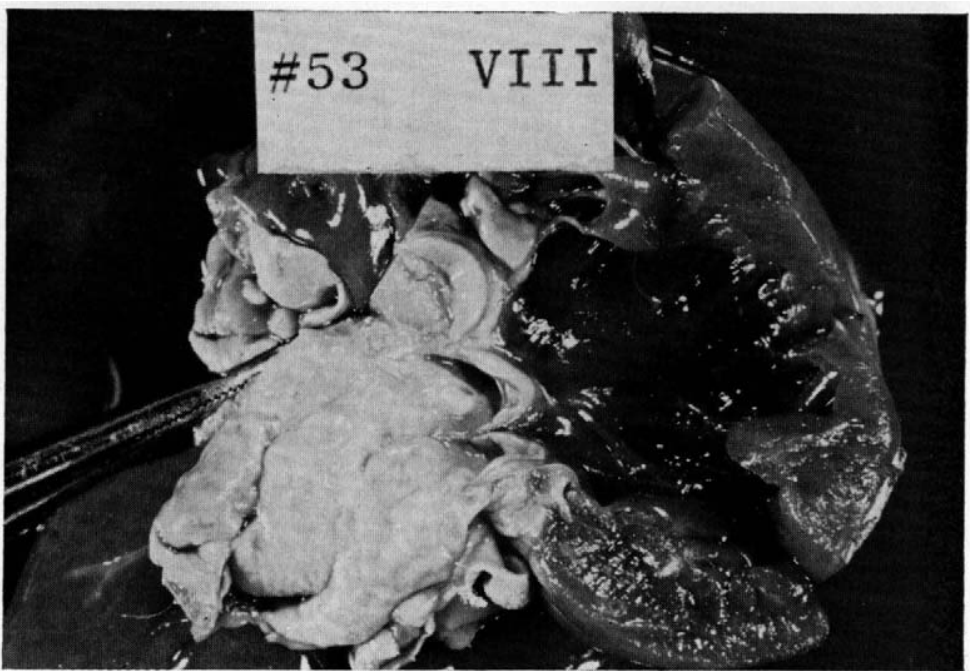

Fra. 3. Gross appearance of heart, pulmonary arteries, and aorta at termination of period IV; $3 \mathrm{a}_{1}$. Group $A$; severe atherosclerosis of ascending aorta, and aortic valves. (Rabbit 53 ; cholesterol $=1014 \mathrm{mg} \%$ at 120 days.) 


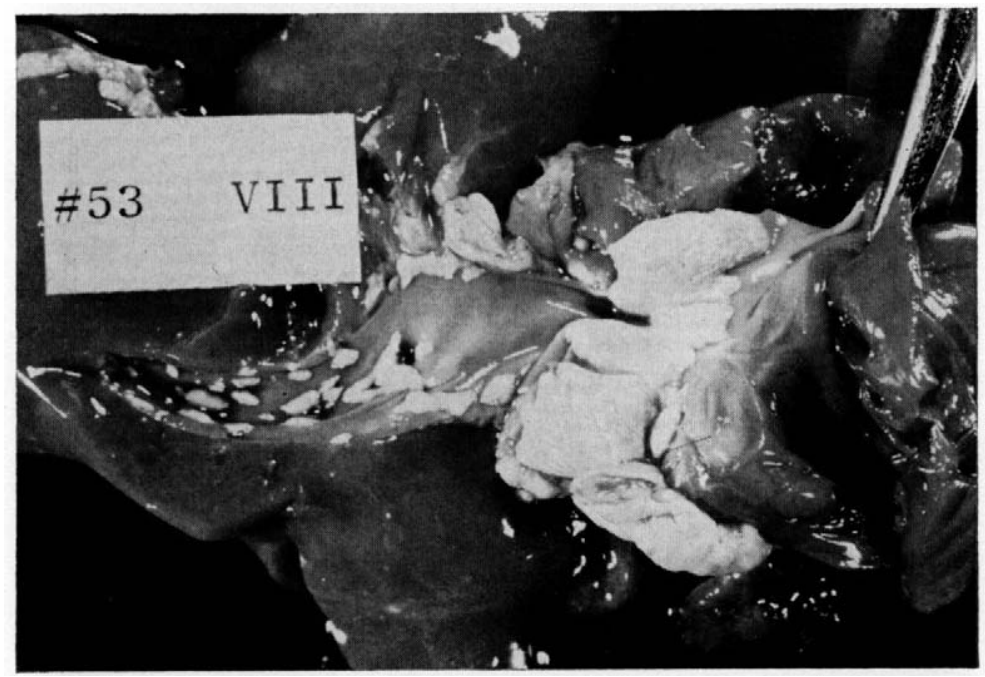

Fig. 3a. Group A; severe atherosclerosis of main pulmonary artery, with moderate involvement above ostia of branch pulmonary arteries. (Rabbit $\$ 53$; cholesterol $=1014 \mathrm{mg} \%$ at 120 days.)

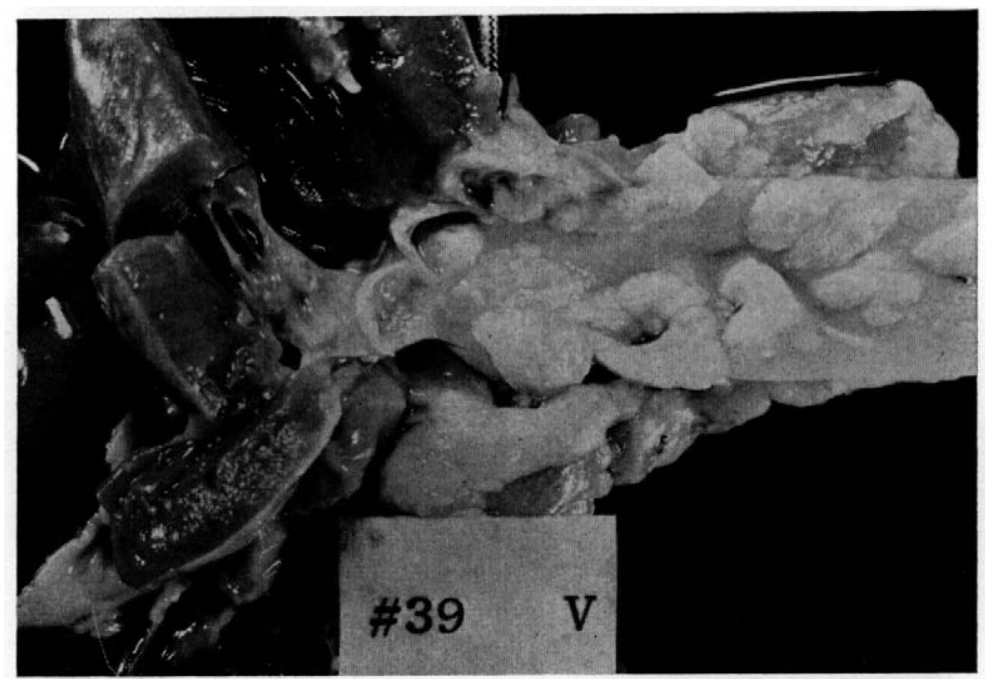

FIG. $3 b_{1 .}$ Group B; moderate atherosclerosis of ascending aorta, and aortic valves. (Rabbit $\$ 39$; cholesterol $=2092 \mathrm{mg} \%$ at 120 days.)

Of the four group $\mathrm{C}$ rabbits autopsied, one had severe atherosclerosis, and one had moderate atherosclerosis (with the thoracic aorta principally involved). The rabbit with severe atherosclerosis, 46 , had an initial cholesterol of 89 $\mathrm{mg} \%, 3,073 \mathrm{mg} \%$ at 30 days, $2,488 \mathrm{mg} \%$ at 60 days, $433 \mathrm{mg} \%$ at 90 days, 181 $\mathrm{mg} \%$ at 120 days, and $100 \mathrm{mg} \%$ at approximately 150 days. The 30 day value 


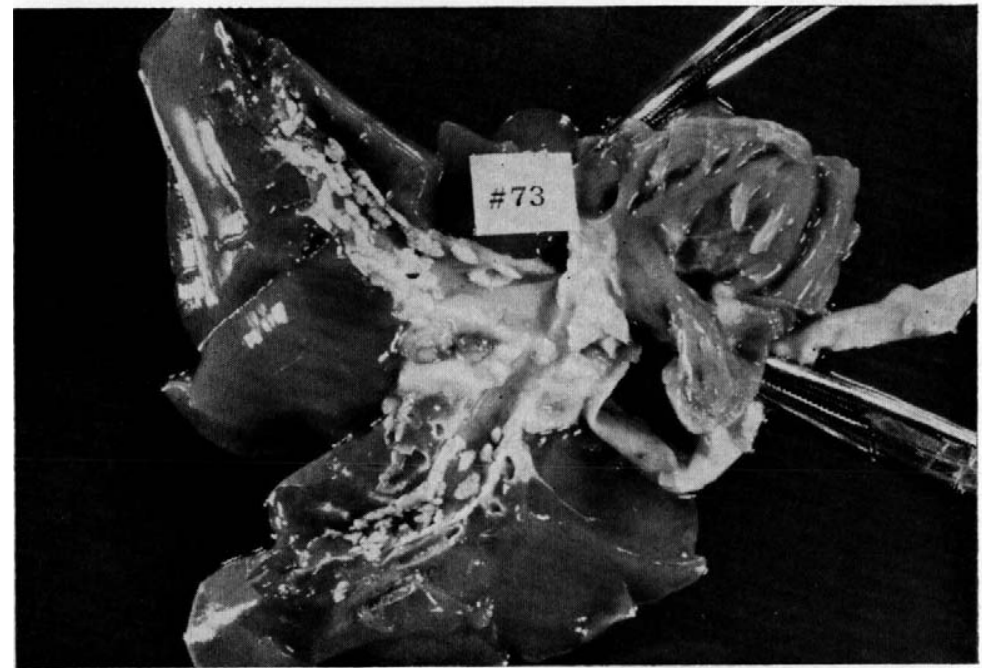

FIG. $3 b_{2}$. Group B; moderate atherosclerosis of pulmonary branch arteries, with severe involvement of main pulmonary artery. (Rabbit 73 ; cholesterol $=1440 \mathrm{mg} \%$ at 60 days, not repeated at 120 or 150 days.)

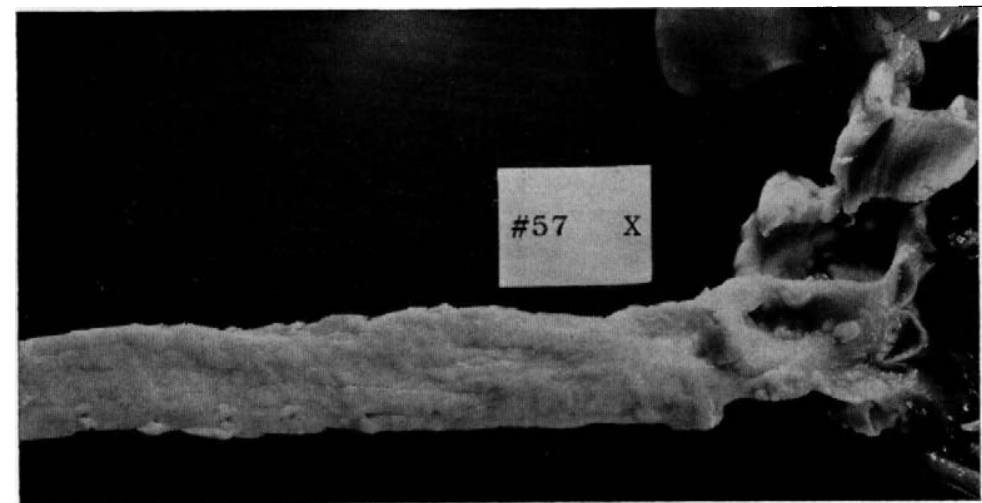

FIG. $3 b_{3 .}$ Group $B$; severe atherosclerosis of ascending arch, and descending thoracic aorta. (Rabbit $\$ 57$; cholesterol $=966 \mathrm{mg} \%$ at 120 days.)

was the highest cholesterol concentration recorded for any animal in the three study groups at this point in time. The animal having moderate atherosclerosis, $\$ 50$, had initial cholesterol of $137 \mathrm{mg} \%, 341 \mathrm{mg} \%$ at 60 days, and $344 \mathrm{mg} \%$ at 90 days. The remaining values were not obtained. The initial value of $137 \mathrm{mg} \%$ was the highest obtained in any animal in the three groups at this point in time. This rabbit had initial and 60-day angiograms, showing no arterial lesions and therefore probably does not represent an animal with the spontaneous vascular lesions described by Schenck, et al., ${ }^{8}$ or by Haust and More. ${ }^{9}$

Two group C rabbits (whose serum cholesterol concentration had risen to $\mathbf{8 8 7}$ and $1,728 \mathrm{mg} \%$ at two months and one month respectively), had no evident 


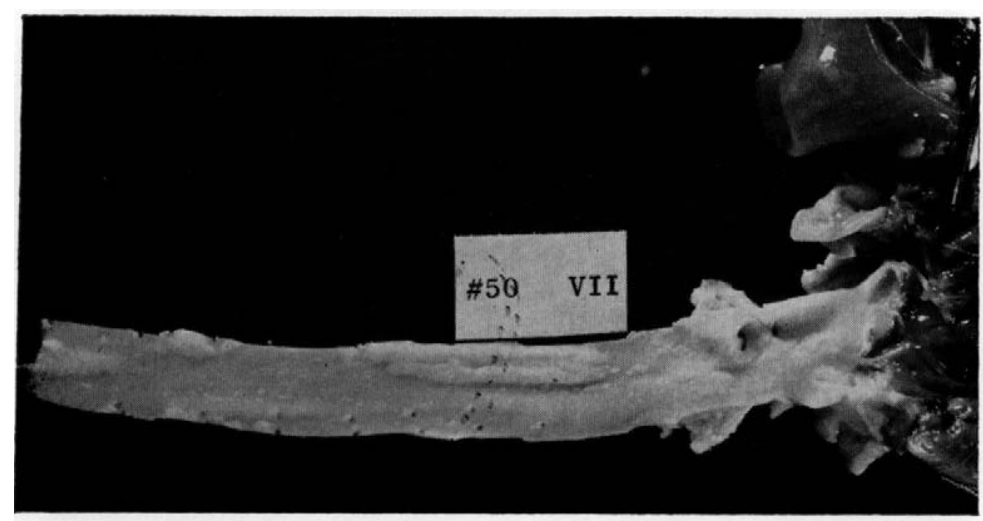

Fia. 3c. Group C; moderate atherosclerosis of thoracic aorta. (Rabbit \$50; initial cholesterol $=137 \mathrm{mg} \% ; 341 \mathrm{mg} \%$ at day $60 ; 344 \mathrm{mg} \%$ at day $90 ; 120$ and 150 day values not done.)

atherosclerosis in the major vessels at autopsy. None of the animals autopsied in groups A or B were free of atherosclerosis.

Figure 3 presents representative examples of the gross appearance of moderate, and severe lesions in groups $\mathrm{A}$ and $\mathrm{B}$, and the moderate involvement of the thoracic aorta in rabbit 50 (group C).

\section{DISCUSSION}

One aspect of this study concerned itself with determining whether angiograms of satisfactory quality could be obtained on repeated occasions in the same animal. The purposes of this study required the obtaining of angiograms on at least three occasions, separated by intervals of several months, this to be done without serious compromise of arterial blood supply. The approach taken is described under Methods. The following appear to be necessary in order to obtain optimum quality of films: 1) for films of the extremity, the use of a nonscreen cassette and placing the limb directly on the cassette; 2 ) preliminary test injections using half-strength Conray ${ }^{\circledR}$, for visualizing the location of catheter tip; 3) use of fine caliber polyethylene radio-opaque catheter material, with appropriate preformed curves. Also important in enabling satisfactory catheter placement is the use of guidewires (.025 o.d.) with "soft" and "hard" tips, which pass freely in the catheters chosen (usually, i.d. .037, o.d. .054 mm).

The catheterization sequence chosen in the first half of the study (initial entry via the right carotid artery; second entry via one femoral artery; third entry via the opposite femoral artery, with ligation of each artery after its use) is an approach which does not require sacrifice of the animal at conclusion of the third study, since collateral supply to the leg is adequate even in the presence of a ligated femoral artery.

From Table 2 and figure 2c, it appears that lesions are radiographically 
demonstrable in the popliteal arteries after two two-month feedings of $1 \%$ cholesterol and 4\% cottonseed oil (interspersed with a one-month period on regular diet, to prevent excessive hepatic lipid infiltration). Unfortunately, the meticulous dissections (under dissecting microscope) which would have been required to remove the femoral and popliteal vessels and to evaluate their lumens were not carried out in this study. We extrapolate from the finding of severe aortic atherosclerosis in most of the animals studied (in groups A and B) that the lesions seen radiographically in the distal leg vessels are also atherosclerotic in nature. However, it cannot be ruled out that these may be purely thrombotic, or perhaps due to some other pathology.

Concerning the question whether clofibrate was associated with less extensive atherosclerosis (or hyperlipidemia), we were unable to demonstrate such an effect in this study. It is obvious that the experimental setting here is decidedly different from the clinical situation in humans. In the present study, only one factor (increased dietary cholesterol intake) is being used to cause atherosclerosis. The dosage is approximately 25 times as high (in relation to $\mathrm{mg}$ cholesterol consumed/day per $\mathrm{Kg}$ body weight) as in humans. While clofibrate's principal known effect is to block endogenous cholesterol synthesis at a point between $\beta$-hydroxy- $\beta$-methyl glutaryl coenzyme-A and mevalonic acid, ${ }^{10,11}$ and while the feeding of large amounts of dietary cholesterol causes feedback inhibition of endogenous cholesterol synthesis in the rabbit, ${ }^{12,13}$ these inhibitory influences on cholesterol synthesis appear inadequate to counterbalance the accumulation of large amounts of exogenous cholesterol. Kritchevsky ${ }^{\mathbf{1 4}}$ has reported results similar to ours, in which two groups of male Dutch belted strain rabbits were fed increased dietary cholesterol $(2 \%$ in $6 \%$ corn oil, one group being fed $0.3 \%$ clofibrate). The serum cholesterol concentrations of both groups were essentially similar, and thoracic aortic atherosclerosis was not less in the clofibrate group, although aortic arch atherosclerosis appeared somewhat.less. Jones, et al., ${ }^{15}$ have demonstrated that hypercholesterolemia and atherosclerosis can be produced in rabbits by feeding a semisynthetic diet containing $20 \%$ beef fat without added cholesterol (producing average cholesterol levels of $369 \mathrm{mg} \%$ in 14 weeks, and $424 \mathrm{mg} \%$ in 18 weeks). Clofibrate, fed at a level of $0.3 \% \mathrm{~W} / \mathrm{W}$ in the diet significantly reduced plasma cholesterol levels in such animals (to 311 $\mathrm{mg} \%$ in 14 weeks, and $322 \mathrm{mg} \%$ in 18 weeks) but had no effect on the severity of the atherosclerotic lesions as compared with the hypercholesterolemic group not fed clofibrate.

Finally, this study has shown the effect of three months of feeding rabbit chow, following two months of $1 \%$ cholestcrol and $4 \%$ cottonseed oil. Serum cholesterol concentration declined from $1,459 \mathrm{mg} \%$ to $154 \mathrm{mg} \%$ after three months of return to rabbit chow diet. The finding of grossly normal vessels in two of four rabbits autopsied in this group (group C) raises the possibility, but does not prove, that atherosclerosis which developed over a two-month period of high cholesterol diet had regressed after three more months of regular dietary 
intake. Armstrong, et al., ${ }^{4}$ have shown regression of lesions in coronary arteries of rhesus monkeys whose atherosclerosis was induced via high cholesterol feeding, and who were subsequently returned to a normal diet. Bortz has shown, ${ }^{\mathbf{1 5}}$ by feeding $1 \%$ cholesterol to female white New Zealand rabbits until serum cholesterol concentrations reached $1,000 \mathrm{mg} \%$ (usually requiring 2-3 weeks), that early but definite aortic atherosclerosis occurred in all 21 animals studied; the cholesterol content of aortas declined after the animals were removed from the cholesterol-elevating diet. The work of these two groups suggests that regression of atherosclerosis in these two species can occur, if the return to normal diet takes place before atherosclerotic lesions have become far-advanced.

\section{SUMMARY}

A method has been described which enables satisfactory angiograms of iliac, femoral, and popliteal arteries of rabbits to be made on three occasions, separated by one or several months. This permits observations to be made, in the same experimental animal, on the effects of various dietary and drug regimens related to the production and regression of large-artery atherosclerotic lesions in these animals.

Stenosing lesions of popliteal arteries were apparent on angiograms in many of the rabbits fed $1 \%$ cholesterol in $4 \%$ cottonseed oil for two two-month periods, with an intervening month of normal diet. Severe aortic and pulmonary artery atherosclerosis also developed in all rabbits so treated.

The addition of clofibrate $0.3 \% \mathrm{~W} / \mathrm{W}$ to one group of rabbits did not significantly change the level of serum cholesterol, or large-vessel atherosclerosis. This lack of effect might be related to the high dose of dietary cholesterol fed, a situation not analogous to the usual multifactorial causation of hypercholesterolemia in humans.

In rabbits rendered hypercholesterolemic by two months of cholesterol-cottonseed oil feeding and then returned to normal diet for three months, a marked decline in serum cholesterol occurred. Three of four of those having final angiograms showed normal vessels by angiography; two of four of those animals autopsied showed no significant large-vessel atherosclerosis. This suggests that regression of atherosclerosis may have occurred, since it has been shown that relatively short-term feeding (2-3 weeks) of $1 \%$ cholesterol can produce atherosclerosis in rabbits.

David R. Bassett, M.D.

Departments of Internal Medicine

University of Michigan Medical Center

Ann Arbor, Mich. 48104

\section{ACKNOWLEDGMENTS}

The authors gratefully acknowledge the technical assistance of Miss Meredith Burr, R.T., Mrs. Sandra Kinderman, R.T., and Miss Pamela Bradley, R.T. 
This study was supported in part by a research grant from the Ayerst Company, and by National Heart Institute Undergraduate Cardiovascular Training Grant, No. HE 5682.

\section{BIBLIOGRAPHY}

1. Anitschkow, N.: Experimental atherosclerosis in animals, in Arteriosclerosis; A Survey of the Problem. Editor, E. V. Cowdry, New York, Macmillan, 1933, pp. 291-294.

2. Rodbard, S., R. Pick, and L. N. Katz: Rate of regression of hypercholesterolemia and atherosclerosis in chicks: Effect of diet, pancreatectomy, estrogens, and thyroid, Circulation, 1954, 10: 597 .

3. Buchwald, H.: Effect of ileal bypass on atherosclerosis and hypercholesterolemia in the rabbit, Surgery, 1965, 58:22.

4. Armstrong, M. L., E. D. Warner, and W. E. Connor: Regression of coronary atheromatosis in rhesus monkeys, Circulation Res., 1970, $27: 59$.

5. Constantinides, P.: Experimental Atherosclerosis, Elsevier Publishing Company, Amsterdam, London, New York, 1965, pp. 25-48.

6. Hilal, S. K.: Hemodynamic changes associated with the intra-arterial injection of contrast media, Radiology, 1966, 86:615.

7. Abell, L. L., B. B. Levy, B. B. Brodie, and F. E. Kendall: A simplified method for the estimation of total cholesterol in serum and demonstration of its specificity, J. Biol. Chem., 1952, 195: 357.

8. Schenk, E. A., E. Gaman, and A. S. Feigenbaum: Spontaneous aortic lesions in rabbits, Circ. Res., 1966, 19: 80 .

9. Haust, M. D., and R. H. More: Spontaneous lesions of the aorta in the rabbit, in Comparative Atherosclerosis, edited by Roberts, J. C., Jr., and R. Straus, Hoeber Medical Division, Harper \& Row, Publishers, New York, Evanston, and London, 1965 , pp. $255-275$.

10. Avoy, D. R., E. A. Swyryd, and R. G. Gould: Effect of $\alpha$-p-chlorophenoxyisobutyryl ethyl ester (CPIB) with and without androsterone on cholesterol biosynthesis in rat liver, J. Lipid Res., 1965, 6:369.

11. Gould, R. G., E. A. Swyryd, D. R. Avoy, and G. Coan: The effects of $\alpha$-p-chlorophenoxyisobutyrate on the synthesis and release into plasma of lipoproteins in rats, in Paoletti, R., D. Steinberg, and D. Kritchevsky, Progress in Biochemical Pharmacology, Basel/New York, S. Karger, 1967, 2:345-357.

12. Dietschy, J. M., and J. D. Wilson: Regulation of cholesterol metabolism, New Eng. J. Med., 1970, 282: 1128, 1179, 1241.

13. Kritchevsky, D., E. Staple, and M. W. Whitehouse: Regulation of cholesterol synthesis and catabolism, Amer. J. Clin. Nutr., 1960, 8: 411.

14. Kritchevsky, D.. P. Sallata, and S. A. Tepper: Influence of ethyl p-chlorophenoxyisobutyrate (CPIB) upon establishment and progression of experimental atherosclerosis in rabbits, J. Atheroscl. Res. 1968, 8: 755.

15. Jones, D., G. A. Gresham, and A. N. Howard: The effect of Atromid on arterial disease induced by semi-synthetic diet in the rabbit, J. Atheroscl. Res., 1963, 3: 716.

16. Bortz, W.: Reversibility of atherosclerosis in cholesterol-fed rabbits, Circ. Res., 1968, 22: 135.

\section{PROCEDURE FOR FEMORAL ARTERIOGRAPHY IN RABBITS}

1. Shave rabbit's ear in the area of marginal vein.

2. Using 23 Butterfly plus 1 cc syringe, inject $1 / 2$ cc atropine sulfate (.4 $\mathrm{mg} / \mathrm{ml}$ ) into marginal vein of ear.

3. Inject 5 cc $2.5 \%$ surital into marginal vein of ear using the same Butterfly catheter, with 5 cc syringe. If, during arteriogram, rabbit emerges from anesthesia, inject additional surital, $1 / 2 \mathrm{cc}$, from time to time as needed.

4. Shave the posterior ventral region and the medial side of the thigh that is to be incised. The femoral artery can be felt pulsating directly beneath the surface.

5 . In the area of incision, make several injections totaling 2 cc of $2 \%$ Sera- 
caine (lidocaine hydrochloride), using a 25 gauge needle and 5 cc syringe.

6. Spray the general area of incision with Betadine solution.

7. Locate the femoral artery by feeling its pulsation. While holding the skin of the area taut, and using a 11 scalpel blade, make an incision longitudinally, ventral to the femoral vein about $3 / 4$ to 1 inch long. The femoral artery is located between the sartorius and gracilis muscles. Loosen the tissue around the femoral artery with curved hemostats, and isolate the femoral artery with a small blunt probe. (In the incision, one encounters, from lateral to medial edge of the incision, femoral nerve, femoral artery, femoral vein, empty space, lymph nodes.) With a cotton swab dipped in $.9 \%$ sodium chloride, clean the femoral artery.

8. When a blood specimen is to be taken, this is done at this point, inserting a catheter proximally and tightening the suture around it. Allow blood to drip into collecting tube, then proceed with step 9 .

9. Draw two pieces surgical silk thread (each approximately one foot), underneath the femoral artery. With one strand, tie off the femoral artery proximally. Loop the other strand in a loose knot distally.

10. While holding the distal thread taut, puncture the femoral artery with a 23 needle. Prepare the catheter assembly (5 cc syringe containing 2 cc $.9 \%$ saline solution, three-way stopcock, and 6 inch straight catheter). The stopcock should be turned in the "off" position.

11. Dilate the puncture of the femoral artery with forceps and insert the catheter distally. First flush with saline, then determine the catheter tip location by injecting 2 cc "dilute contrast material" (Conray, diluted to $30 \%$ ) observing by image intensifier. When catheter is properly positioned, affix the catheter firmly in the femoral artery by tightening the knot of the distal ligature. Using a 5 cc syringe, steadily and continuously inject 2 cc $60 \%$ Conray into the artery. When $1 \frac{1 / 2}{2 c}$ has been injected, operator calls for radiographic exposure to be made, then completes remainder of injection. (See below for radiographic conditions.)

12. After radiographic exposure, flush the artery with 3 cc of $0.9 \%$ sodium chloride.

13. Following the obtaining of satisfactory angiograms, the skin is closed with interrupted stitches (surgical thread, silk, gauge 00 attached to atraumatic surgical needle).

14. Inject 1 cc penicillin (21 gauge needle) into gracilis muscle, if animal is to be saved.

The following materials should be immediately accessible before proceeding with arteriography:

10 cc syringe (labelled $60 \%$ Conray)

10 cc syringe (labelled $.9 \%$ sodium chloride)

10 cc syringe (labelled " $30 \%$ Conray dem")

cotton swabs

2 pair curved hemostats 
surgical thread (silk, gauge 00 ) two one-foot lengths atraumatic surgical needle with 00 silk thread affixed iris scissors

blunt probe

small forceps

catheters (size and shape determined by procedure [i.d. .037 ; o.d. .054 inches])

guidewire (.025 inches o.d. with "soft" and "hard" ends)

Safety guidewire, movable core; catalogue $\mathrm{sf-25-125}$

o.d. .025 inches, length $125 \mathrm{~cm}$. Also t*m-25-125

o.d. .025 inches, $125 \mathrm{~cm}$ length

${ }^{*} \mathrm{t}=$ teflon coating

Cook, Incorporated, Bloomington, Indiana 47401

three-way stopcock, disposable, sterile Pharmaseal k75

6 French Luer-lock adaptors

scalpel

11 scalpel blade

Solutions for angiographic procedures

Sterile .9\% sodium chloride Surital ${ }^{\circledR}$ (sodium thiamylal) (Parke Davis and Company) (prepare as $2.5 \%$ solution with sterile water for injection.)

Sericaine (lidocaine hydrochloride) $2 \%$ (Rachelle Laboratories)

Conray (Meglumine iothalamate) 60\% Mallinckrodt Pharmaceuticals.

\section{Disposable items needed}

Butterfly-23 infusion set (scalp vein infusion set, with attached 23 gauge needle). Abbott Laboratories.

Syringes; 5 cc B-D sterile disposable; 10 cc syringes B-D sterile disposable. Needles 21,23 gauge B-D, 11/4 inches.

B-D Yale 25 gauge $5 / 8$ inches.

Scalpel blade 11 Bard Parker Company, Inc.

\section{Radiographic Conditions}

Radiographs were made with a General Electric Model $11 \mathrm{fp} 6$ with a $2 \mathrm{~mm}$ $\mathrm{X}$-ray source. Focal spot to object distance was 38 inches for abdominal films, 40 inches for leg films. Object to film distance was 2 inches for abdominal exposures; lower limbs were placed directly on X-ray film in "Redypack containers. For abdominal exposures, 12.1 Potter-Buckey grid was used, with 80 lines per inch; a screen casette was also used, with 40 -inch distance to Buckey. For limb exposures, a Kodak "Redypack" ${ }^{\circledR}$ " was used, with 40 -inch distance to table. Kodak "Royal Blue" film was used. Exposure factors were $300 \mathrm{MA}$ at $1 / 10$ second at $50 \mathrm{KV}$ for abdominal exposures (with casette); $300 \mathrm{MA}$ at 1/10 second at $88 \mathrm{KV}$ for leg exposures. Film was developed for 3 minutes in Kodak $\mathrm{X}$-ray developer. 


\section{REFERENCES}

1. Adams, D. R., Olin, T. B., Redman, H. C.: Catheterization of arteries in the rabbit, Radiology 84: 531, March 1965.

2. Redman, H. C., Berg, N. O., and Boijsen, E.: Absence of toxicity of contrast media in the superior mesenteric artery. A pathologic goal study in rabbits, Invest. Radiology 2 : $123,1967$.

3. Roentgen Techniques in Laboratory Animals, Felson, Benjamin, editor, W. B. Saunders Company, 1968. Philadelphia, 245 pages.

4. Tirman, W.'S., Caylar, C. E., Banker, H. W., and Caylor, T. E.: Microangiography. Its application to the study of the vascular anatomy of certain organs of the rabbit. Radiology 57:70,1957. Angiography: Recent Developments, Methodology, and Clinical Usefulness (booklet prepared by Mead Johnson Laboratories, 1967, 31 pages). (Includes 54 methodologic references.) 


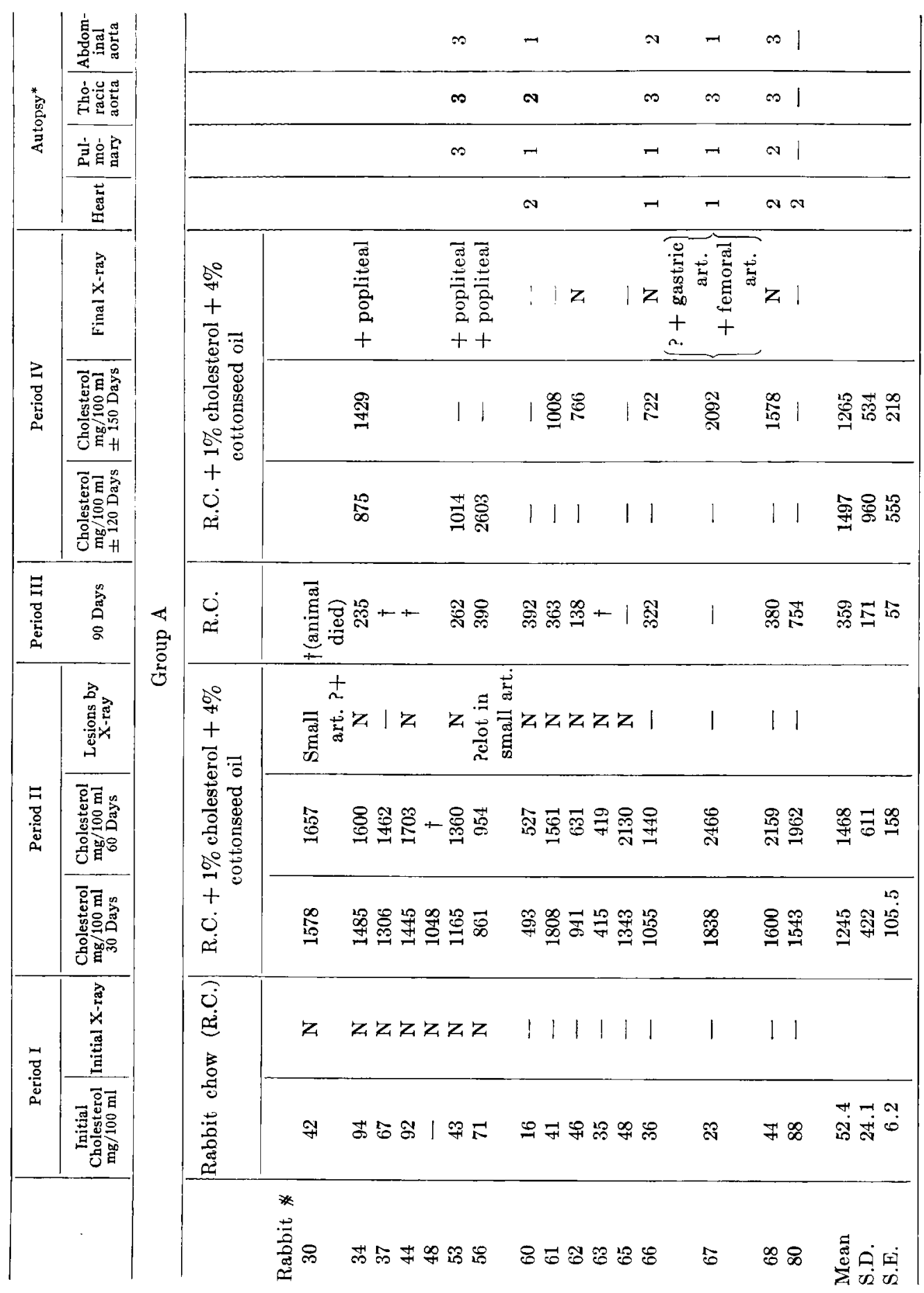




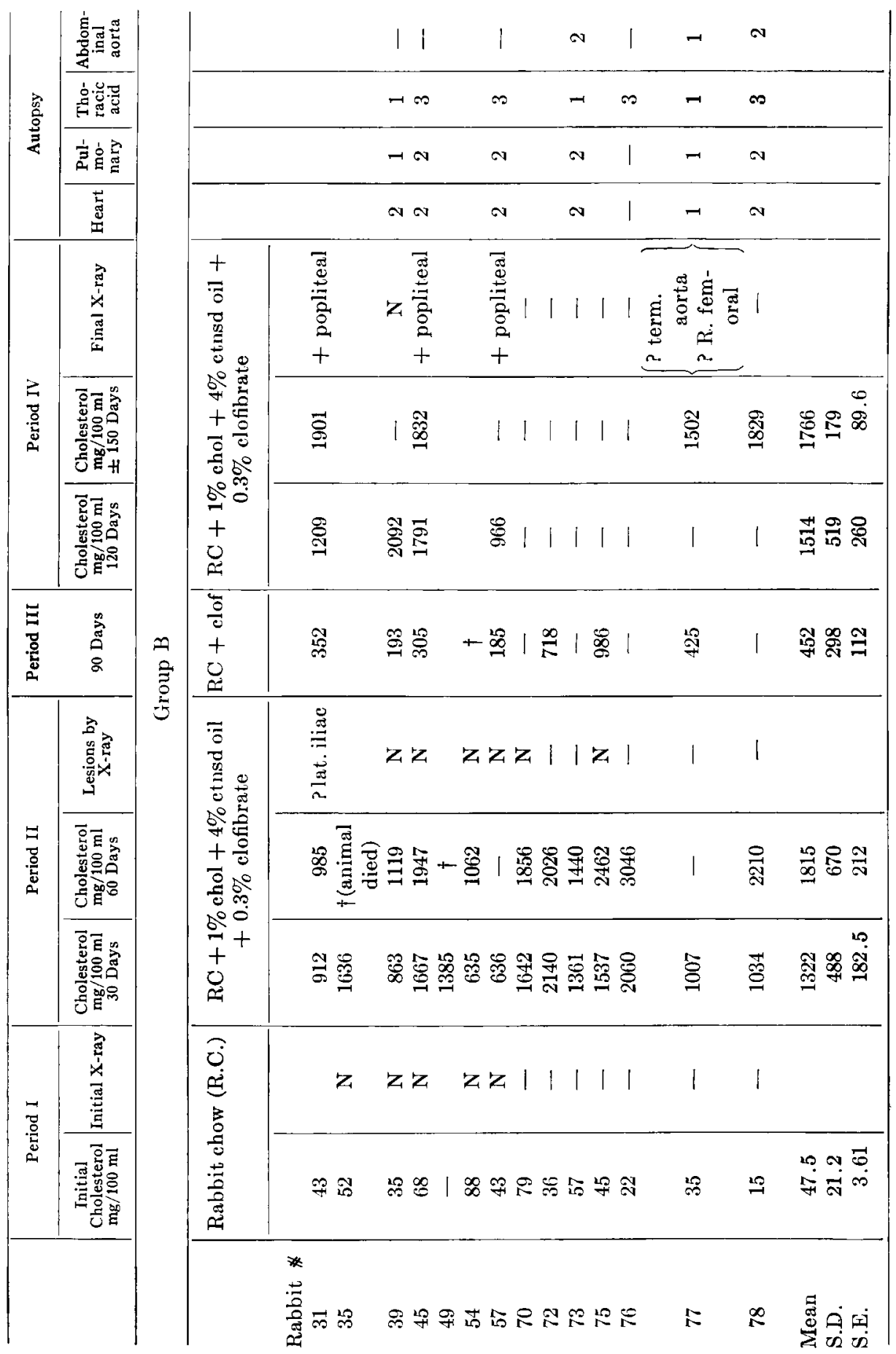


ARTERIAL LESIONS IN CHOLESTEROL-FED RABBITS

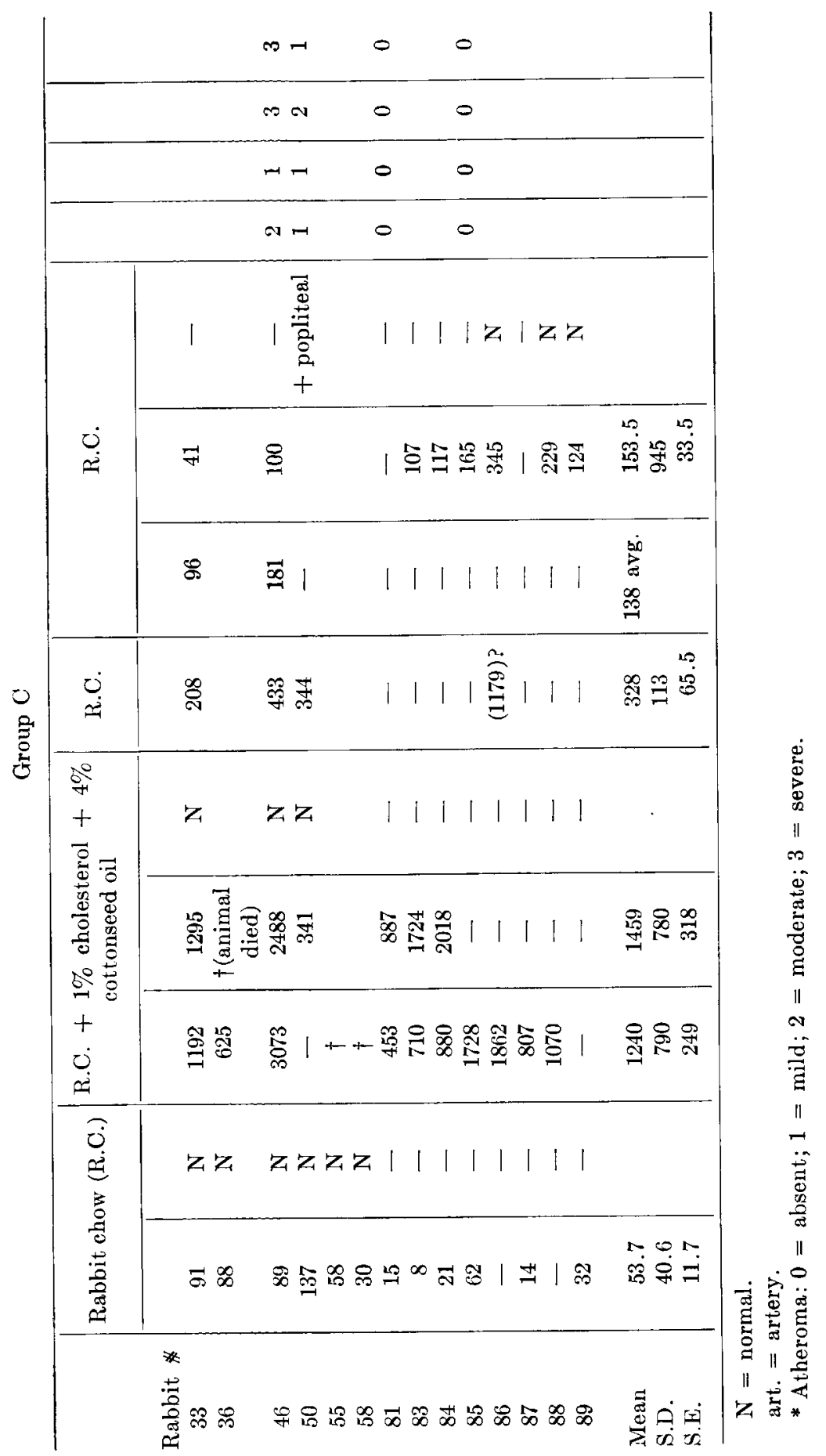

